\title{
¡Caramba! Una panorámica
}

\author{
Octavio Beares y Gerardo Vilches
}




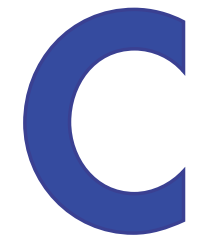

UANDo Manuel Bartual y Alba Diethelm decidieron que era buen momento para montar un fanzine en torno al humor, allá por 2011, lo hacían contando con el hecho de que internet, Youtube y las redes sociales eran ya un espacio comunicativo consolidado, uno con el que el lector medio de cómics está familiarizado, lo utiliza y es proclive a sus avances. $¡$ Caramba!, el fanzine, nace como proyecto de su tiempo, $\mathrm{y}$ tantea formas novedosas. Lo primero que se supo del tema fue lo que entendemos como un bype o incluso un viral: a finales de mayo se difundió por la red un vídeo en el que personas reconocidas del mundo del cómic - y algún anónimo- pronuncian enigmáticamente la exclamación “¡Caramba!” mirando a cámara. Paco Roca, Carlos Vermut, Alberto García Marcos, Paco Alcázar, Manel Fontdevila, Mireia Pérez o Daniel Ausente, entre otros, movieron a la curiosidad en línea. ¿Qué es esto? "A la venta el 6 de junio”, cerraba el clip.

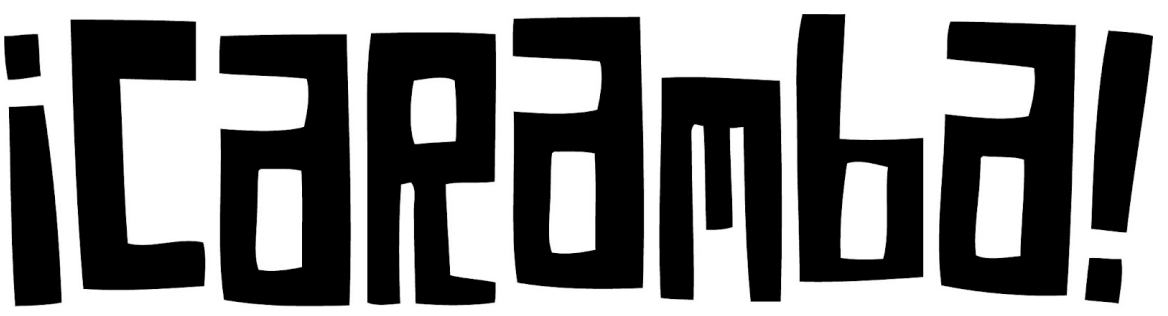

Logotipo de ¡Caramba!

Se estaba creando una expectativa sobre el lanzamiento una semana después, el 6 de junio de 2011, del fanzine ;Caramba!. Es decir: se estaba apostando por internet como medio de difusión. Y una vez el fanzine ya era una realidad, también como medio de adquisición. ; $C a-$ ramba! fue una revista en la que participaron algunos de los principales nombres propios del cómic de humor español, y tenía como norte temático al propio humor, su sentido último. En sus páginas firmaron Albert Monteys, López Rubiño, Joan Cornellà, Mauro Entrialgo, Juanele, Rubén Fdez., Jorge Parras, Raúl Minchinela y Puño, Bernardo Vergara, Santiago García y Javier Olivares, Jorge de Cascante, Laura Pacheco, Sergio Córdoba y Juaco Vizuete, Manuel Castaño, Guille Martínez-Vela, José Luis Ágreda, Carlos de Diego, Luis Bustos, Juarma, Clara Soriano, John Tones y Guitián, Paco Alcázar, Andrés Palomino, Néstor F, Manel Fontdevila y Pedro Vera.

La intensiva campaña y el crédito de su plantel de colaboradores fueron correspondidos por la atención mediática, y la respuesta del lector fue buena. Gozó de dos ediciones sumando entre ambas una tirada total de 999 ejemplares, y se agotó entera en apenas un mes. ${ }^{1} \mathrm{La}$ perspectiva era óptima y durante ese verano se fraguó el proyecto de la editorial. Una editorial que tenía claras sus coordenadas, marcadas por el fanzine. Su eje sería el cómic de humor - de todo tipo-, un marco genérico que el contexto de su tiempo — la novela grá-

1 “CCaramba! ¡Se agotó!”, disponible on line en <http://carambacomics.com/blog/caramba-se-agoto/>. 5 de julio de 2011. Consultado el 9 de julio de 2015. 
fica consolidando la idea del cómic maduro de contenidos "serios" - sonaba casi original. $\mathrm{Su}$ medio principal será internet, entendida tanto como principal canal publicitario como en tanto que lugar preferente de ventas. La web de ¡Caramba! promueve desde entonces la facilidad del mercado electrónico, pues asume los gastos de envío y ofrece obsequios exclusivos al comprador digital. Pero no se abandonaría la distribución tradicional, de forma que su catálogo puede encontrarse igualmente en varias librerías físicas.

Por otro lado, uno de los objetivos principales de la nueva editorial fue, en palabras de Manuel Bartual, averiguar "si el reparto de beneficios para el autor podía ser otro". ${ }^{2}$ El reparto del p.v.p. de un libro destina, en el mejor de los casos, un 10\% para el autor del mismo. Con el modelo ideado para ¡Caramba!, los beneficios de cada producto se destinan en primer lugar a pagar los gastos de imprenta del mismo, y una vez cubiertos, se reparten al 50\% entre editores y autor, sin que exista ningún adelanto sobre esos beneficios para este último. De este modo el autor comparte los riesgos con la editorial: si las ventas son malas, ambos pierden, pero si son buenas, el autor gana más de lo que ganaría en el modelo de negocio tradicional. Sobre el balance de esta apuesta no nos extendemos porque el propio Bartual nos ha proporcionado datos. ${ }^{3}$

Desde los inicios de la editorial Bartual y Diethelm han apostado por autores de su interés y obras que podían defender no solo desde criterios comerciales, sino también desde sus gustos personales. De hecho, varios de los autores que han publicado con la editorial mantienen vínculos de amistad o profesionales con ellos - Manel Fontdevila, Carlos Vermut o Paco Alcázar, entre otros-. Y dado que se intentará que internet sea el primer canal de venta, también hay una intención manifiesta de publicar en papel a autores que han obtenido ya cierto éxito en la red. El segundo lanzamiento de la editorial ya responde a esto: Laura y Carmen Pacheco, autoras de Let's Pacheco, publicaban un exitoso weblog previamente. Otros ejemplos claros son Xabi Tolosa, autor de Esto se ha hecho mil veces, o Alberto González Vázquez, autor de Humor cristiano, aunque sin duda el caso más significativo es el Hematocrítico, pseudónimo de Miguel Ángel López, un personaje tremendamente popular en redes sociales, que mantiene varios Tumblr humorísticos. Con ¡Caramba! ha publicado El Hematocrítico del arte, El Hematocrítico del arte ${ }^{2}$ y Drama en el portal, con material de dichos Tumblr y una parte inédita.

Esa sinergia entre la edición analógica y el mundo digital también se ha plasmado, durante toda la trayectoria de ¡Caramba!, en los métodos de promoción. Desde el comienzo, casi cada título se ha visto acompañado de vídeos promocionales que buscaban la viralidad pero que también eran piezas artísticas, en algunos casos obra de los mismos autores de los cómics. Uno de los casos más notables fueron los vídeos para las ediciones de Humor cristiano de Alberto González Vázquez. ${ }^{4}$ Pero, además, la acción en internet y redes sociales —en las que ¡Caramba! participa con un perfil de activa presencia desde sus inicios- se llevó un paso más allá al proponer una presentación de una de sus novedades en directo, a través de emisión en streaming. Fue el caso de La industria de los sueños de Paco Alcázar, cuya presentación tuvo lugar el 14 de marzo de 2012, con la conducción de Alberto García Marcos.

\footnotetext{
2 En entrevista publicada en esta misma revista, p. 88.

3 En entrevista publicada en esta misma revista, p. 92.

${ }^{4}$ Sirva de ejemplo el primero de ellos, disponible on line en <https://vimeo.com/43094405>, consultado el 9 de julio de 2015 .
} 
La media de cien conectados y el máximo de doscientos ${ }^{5}$ supera ampliamente al público habitual de este tipo de eventos cuando son presenciales, aunque ¡Caramba! también ha realizado numerosas presentaciones tradicionales y sesiones de firmas.

Con esta definición de intereses, modelo editor, relaciones con el autor y modos de promo-

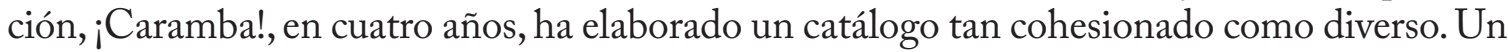
montante de 36 productos entre cómics y merchandising -incluyendo los tres lanzamientos bajo el paraguas de Astiberri-. Está claro que el cómic es la columna vertebral de la editorial, pero en su catálogo encontramos también juegos de postales o láminas, libros ilustrados como los productos ya referidos de $\mathrm{El}$ Hematocrítico, un póster y hasta una camiseta.

Centrándonos en sus cómics, estos han buscado siempre una reflexión en torno al valor del formato. En este sentido la primera referencia de ¡Caramba!, Reunión de Manel Fontedvila ya supone una apuesta por la originalidad. Un cuaderno de bocetos que editan precisamente como cuaderno de dibujo, en cartoné con anillas. A partir de aquí, en el catálogo podemos encontrar álbumes en cartoné —Let's Pacheco!-, libros en rústica - Humor cristiano- o la reivindicación del comic-book que es la colección Jaimito, iniciada en octubre de 2012 con Ser un hombre: Cómo y por qué de Albet Monteys, y que defiende el cuadernillo grapado como, también, objeto estético. La pirueta más original en esta exploración de los formatos del cómic será el número dos del fanzine que bautizó a la editorial: un cómic de cinco metros de largo, enrollado y contenido en un tubo de cartón duro con tapas plásticas.

Conocida la historia, la calidad media y los modos casi revolucionarios de relacionarse con el cliente de ¡Caramba!, se entiende que no haya caído en saco roto. Su probada viabilidad económica en el contexto de una independencia insobornable y una apuesta por el autor ha calado en nuevas editoriales surgidas en España en los últimos años. Un buen ejemplo de ello sería Entrecomics Comics, donde se sigue el modelo de defender la red como cordón umbilical entre el lector y el editor, y sobre todo el marco de nuevas relaciones autor-editor establecido por Bartual, con el concurso también de nombres consagrados — Luis Bustos o Pep Brocal-y debutantes —Pablo Ríos—, aunque con una orientación más heterogénea donde caben todos los géneros narrativos.

Hay un caso especial en el que hay que detenerse. Orgullo y Satisfacción es un proyecto que no solo cabe mencionar como herencia más o menos directa del modelo ¡Caramba! - humor como eje, independencia, la preeminencia del autor-: su número cero, surgido en 2014 como manifiesto librepensador de la diáspora de autores originada por la censura de RBA a una portada antimonárquica de El Jueves, apareció editado por ¡Caramba! —y diseñado y maquetado por Manuel Bartual y Alba Diethelm-. La experiencia en el mercado "virtual" que había ensayado ¡Caramba! los años anteriores se aprovecha de esta nueva iniciativa, ya solo vinculada al archivo digital en descarga directa, legal y no gratuita, aunque los siguientes números fueron editados bajo el sello, simplemente, de Orgullo y satisfacción. Por otro lado, el primer libro físico de Orgullo y Satisfacción, El diccionario ilustrado de la democracia española, lo edita ¡Caramba! , ya como sello de Astiberri, y por descontado, lo vende no solo en librerías de toda España, sino también a través de la web de la editorial.

${ }^{5}$ En entrevista publicada en esta misma revista, p. 89. 
El último capítulo importante en la trayectoria de ¡Caramba! es su vinculación a Astiberri. La compra del sello por la editorial bilbaína se hace pública en enero de 2015 por parte de ambas partes. Desde ¡Caramba! se explica que "para continuar creciendo acabamos de cerrar un acuerdo: en 2015 ¡Caramba! se integra en la estructura editorial de Astiberri como sello editorial, manteniendo la línea que hemos marcado desde nuestros inicios". ${ }^{6}$ Este acuerdo permite un marco de distribución y gestión más holgado en tiendas especializadas y librerías generalistas y respeta la idiosincrasia de ¡Caramba!, si bien replantea el reparto de beneficios con el autor, que pasa del 50\% del modelo previo, al aplicado por Astiberri: cobrar un 10\% y trabajar con un adelanto. ${ }^{7}$ En esta nueva etapa se estrena el sello con una recuperación histórica, el Mondo Lirondo de La Peñya —editado por primera vez en formato comic-book por Camaleón Ediciones en 1993- al que acompañó en un interesante golpe de efecto un nuevo libro, de idéntico formato, con nuevo material: Mondo Lirondo Returns. El último lanzamiento es el Diccionario ilustrado de la democracia española, que agotaría su primera tirada en dos semanas. ${ }^{8}$

Al margen de la calidad individual de cada una de sus obras, la experiencia de edición independiente de los primeros cuatro años de vida de ¡Caramba! aportó al mercado español un ejemplo de cómo podían emplearse las herramientas tecnológicas para generar nuevas dinámicas y encontrar vías de negocio inéditas. Demostró a todos los actores implicados en el mercado editorial que era posible hacer las cosas de un modo nuevo, prescindiendo de intermediarios y ofreciendo unas condiciones diferentes a los autores. Lo que Alba Diethelm y Manuel Bartual no pudieron anticipar fue que el éxito comercial de parte de sus lanzamientos multiplicaría exponencialmente la carga de trabajo, hasta llegar a un punto de no retorno en el que se hacía imposible asumir ese volumen. Paradójicamente, fue ese éxito comercial y no la falta del mismo lo que hizo necesario un cambio en el modelo. Por otro lado, tal y como explica Bartual, la editorial no reportaba aún beneficios a sus editores debido a todos los gastos derivados de su actividad. ${ }^{9}$

De entre todas las opciones posibles, Diethelm y Bartual escogieron integrarse en una estructura editorial sólida y que conocían bien, la de Astiberri, de cuyo capital el propio Bartual participaba. Ambos mantienen el control sobre los productos publicados y deciden los títulos, lo que garantiza que seguiremos viendo obras interesantes. Pero más allá de eso, su aventura inicial pasará a la historia como una de las experiencias alternativas de mercado más innovadoras del cómic español reciente.

A continuación ofrecemos un repaso a todo el catálogo de ¡Caramba! en sus primeros años como editorial independiente, en forma de reseñas breves.

6 “¡Caramba! en 2015”, disponible on line en < http://carambacomics.com/blog/caramba-en-2015/>. 16 de enero de 2015. Consultado el 9 de julio de 2015.

7 En entrevista publicada en esta misma revista, p. 92.

${ }^{8}$ En Facebook lo celebra el propio perfil de Orgullo y Satisfacción, disponible on line en < https://www.facebook. com/orgulloysatisfa/photos/a.233129143563942.1073741828.232985783578278/362063217337200/?type=1\&theater/>. 10 de junio de 2015. Consultado el 9 de julio de 2015 .

9 En entrevista publicada en esta misma revista, pp. 90-91. 


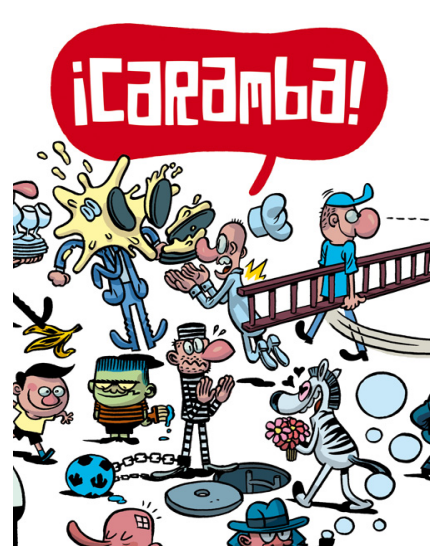

\section{¡Caramba! 1}

Varios autores, 2011

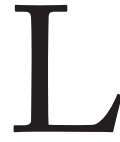

A historia de ¡Caramba! empezó con el primer número de un fanzine colaborativo que reunió a algunos de los autores más importantes de su momento. Paco Alcázar, Mauro Entrialgo, Javier Olivares, Santiago García, Guitián, Puño, Albert Monteys y un largo etcétera unidos a conocidas plumas de la cultura pop como John Tones o Raúl Minchinela, se organizan en torno al concepto mismo del humor, que exploran desde puntos de vista variados. Desde los metachistes - Jaimito, la mosca en la sopa, el francés, el inglés y el español- al ensayo gráfico sobre los límites del humor, pasando por la magnífica historieta biográfica sobre Josep Coll del dúo García / Olivares, hay en las páginas de este fanzine muchos aciertos, pero si hay que destacar uno, debe ser la genial idea de contar la visita de David Lynch a Lepe de Carlos de Diego. El éxito de este cómic, que se vendió on line acompañado de varios regalos, fue decisivo para Manuel Bartual y Alba Diethelm. GV

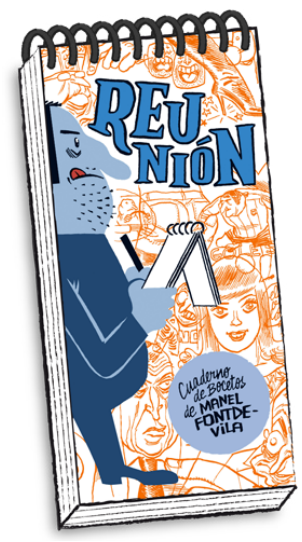

\section{Reunión}

Manel Fontdevila, 2011

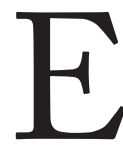

L primer título publicado por ¡Caramba! como editorial no fue un cómic convencional. Reunión se publicó con un formato de libreta que imitaba las que Fontdevila usaba para tomar notas y garabatear durante las reuniones de redacción de El Juerves. El resultado es un compendio sin orden y concierto de esos garabatos rápidos, que tienen la magia del dibujo espontáneo y directo, sin borrar ni corregir. El dibujo automático, realizado mientras la mente está ocupada en otras tareas, revela inesperadas asociaciones de ideas y joyas surrealistas que se mezclan con las citas a la actualidad, anotadas como posibles temas para la revista. Fontdevila, un dibujante nato y compulsivo, tiene más ideas de las que podría dibujar. El divagar de su mente en Reunión está guiado por el disfrute que le genera el mero acto de trazar líneas en un papel, solo que donde los demás hacemos monigotes, el destila perlas. Por momentos, la hilazón de conceptos recuerda a Superputa (Glénat, 2007), una de sus obras más incomprendidas. Esta original libreta llena de apretados dibujos y caligrafías barrocas tal vez no pueda considerarse una "obra" en un sentido estricto, pero es mucho más que un artículo curioso para completistas de Fontdevila. GV 


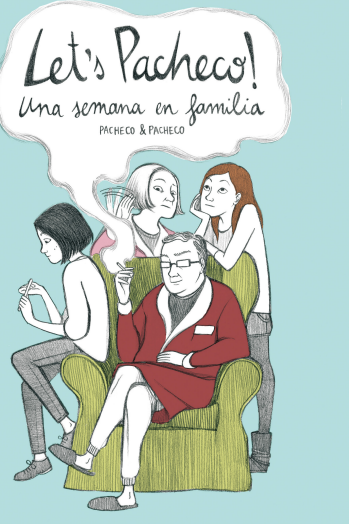

\section{Let's Pacheco}

\section{Pacheco \& Pacheco, 2011}

U NA de las facetas que pronto mimaría la editorial ${ } \mathrm{Ca}^{-}$ ramba! es la de buscar en internet a autores interesantes. El weblog Let's Pacheco nació como reto personal para una joven restauradora sin trabajo, y pronto la firma de Laura Pacheco comenzó a sonar como una de las más frescas de la temporada. Con un dibujo muy maduro pese a sus claros referentes (Kate Beaton), un humor cotidiano familiar y un sentido del realismo mágico entrañable, su webcómic no pasó inadvertido. En 2012 y con el apoyo de su hermana Carmen, escritora de literatura juvenil — que ya colaboraba en el original on line-, publica Let's Pacheco. Una semana en familia. En esta novela gráfica se relata lo que el título describe, según el patrón de reencuentro familiar: un compendio de situaciones hogareñas algo alocadas donde la armonía nace del caos y del choque de personalidades. La hermana favorita, el padre "difícil", la visita a los lugares añorados... ítems recurrentes de este tipo de historias familiares que las hermanas Pacheco emplean para encontrar lugares anímicos reconocibles. Un cómic de dibujo expresivo y muy agradable que se supedita al avance a través de gags casi autónomos, y al que se le podía pedir algo más de vitriolo. $\mathrm{O}$ no, porque el cariño que destila es reconfortante. ов

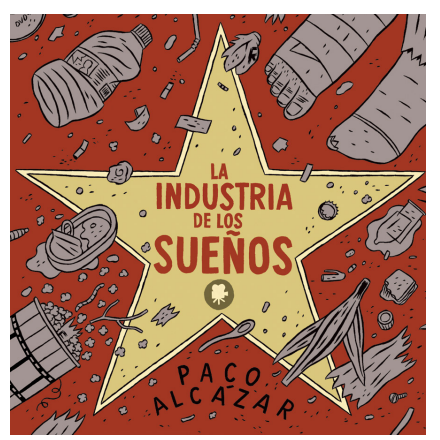

\section{La industria de los sueños}

\section{Paco Alcázar, 2012}

$\mathrm{E}$ aplicarse a Paco Alcázar. Desde luego determinadas truculencias quedan fuera de este trabajo, pero la recopilación de estas viñetas supone un buen surtido de psicosis, lloriqueos e ideas retorcidas. Sin duda, el libro se disfruta más si se conocen los referentes que aparecen, pero tampoco hace falta ser un cinéfilo de pro para reírse con chistes que deben todo a los diálogos: no hay apenas acción, sino más bien ideas y conceptos expresados textualmente. Es especialmente divertido observar cómo Alcázar se lleva la caricatura de los personajes a su terreno gráfico - esto es: que no se parecen en absoluto-y, sobre todo, darse cuenta de cómo su personalidad inunda hasta un trabajo de encargo como este, dirigido a un público muy amplio. La aparición de secciones recurrentes - "Sólo es una sugerencia"; "Acongojante"- ayuda a que la acumulación potencie la diversión, aunque también se disfruta mucho saltando de chiste en chiste. GV 


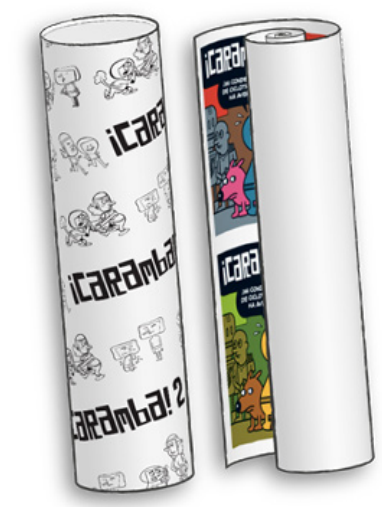

\section{¡Caramba! 2}

Varios autores, 2012

Y A asentada como editorial en el mercado, ¡Caramba! vuelve a lanzar su fanzine homónimo en una clara apuesta por seguir vinculada a sus orígenes. El número 2 es un despiporre y uno de los artefactos más originales que el mundo del cómic puede enarbolar: 47 autores - no toca enumerarlos todos- y un formato de esos de poner cara de bobo, ¡un rollo de papel que desenrollado alcanza los cinco metros! Por encima de las circunstancias epatantes y la sonrisa involuntaria que provoca esta pirueta formal, lo que destaca finalmente es un hecho: las ganas indisimuladas de divertirse con la locura. Dos líneas narrativas (la fila superior y la inferior) que arrancan con una doble viñeta de Manuel Bartual para que los demás autores las desarrollen sin guión previo o posterior. Una viñeta por firma y libertad total, solo una traca final más orquestada y leves indicaciones de gama cromática para cada fila. El juego es intentar ponérselo muy difícil a quien te suceda para, así, lograr una lectura absurda pero divertidísima. Mi momento favorito, puestos a jugar también desde el lado del lector, sería la viñeta de David Aja, una vacilada fina a costa de Marvel (“ $; A$ esas criaturas les ha sido robada la libertad de elección!”, dice el protagonista) y de Jack Kirby. OB

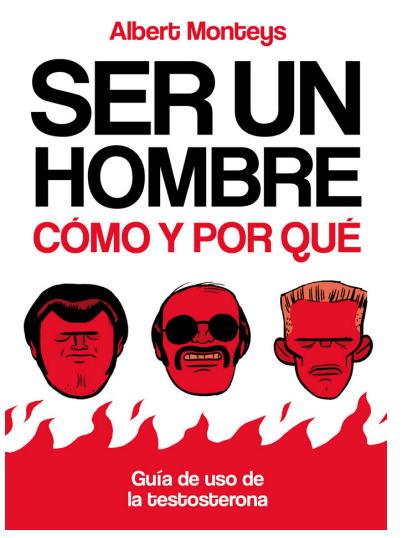

\section{Ser un hombre: Cómo y porqué}

Albert Monteys, 2012

Colección Jaimito n. ${ }^{\circ} 1$

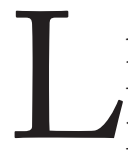

A colección Jaimito tiene en este título inaugural una de las joyas de la corona de ¡Caramba!. El sello que apostó por el humor edita con esta pieza uno de los trabajos más descacharrantes de Albert Monteys y quizá de su propio catálogo editorial. Imprescindible y ácido "manual para machos", Monteys exprime en sus páginas todo su talento cómico desde el subtítulo - "Guía de uso de la testosterona" - hasta el perfil autoral de la solapa de contraportada- "Lleva ya 20 años dibujando cómics que son consumidos principalmente por hombres, lo que le ha permitido observarlos de cerca y estudiarlos a conciencia"-. En sus 24 páginas Ser un hombre: Cómo y porqué es todo chicha y ofrece auténticos alardes de composición; dibujos hilarantes — una de las mayores virtudes de Monteys es su facilidad para hacernos reír con su dibujo-; ideas locas como la defensa de la desnudez masculina en cualquier situación, incluidas entrevistas laborales; o críticas al saludo con mano blanda. Pero su punto álgido es una pirueta que vale por muchos cómics: "El mapa del sexo", una vacilada a la fantasía heroica y sus mundos inventados/cartografiados, con un plano en el que perderse mucho tiempo y no parar de reír, el reverso con dos cojones de la aldea pitufa y sus alrededores. Con este arsenal la ironía fina del autor ha dibujado a un españolito medio - ¿O a un varón común, en general? - que no está tan superado. ов 


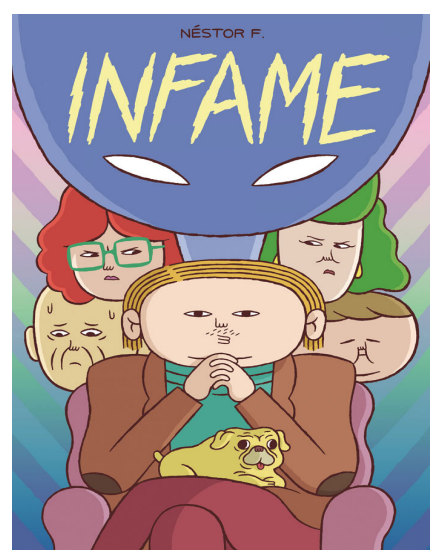

\section{Infame}

\section{Néstor F., 2012}

Colección Jaimito n. 2

de Twitter para su personaje protagonista: Bruno Kolin, un mezquino crítico de cómics que le servía para parodiar el sector editorial al plantear un mundo en el que la crítica de cómics podía ocupar espacio en un magazine televisivo. El problema de Infame fue que el patetismo genial del personaje tuitero no quedaba reflejado más allá de alguna escena aislada - lo mejor del cómic, una conversación entre críticos totalmente deprimente- $y$, de hecho, derivaba enseguida a una aventura de impecable factura gráfica pero que dejaba con ganas de más. GV

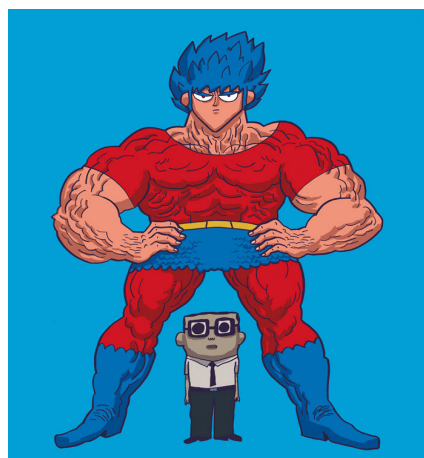

COSMIC DRAGON

\section{Cosmic Dragon}

\author{
Carlos Vermut, 2012 \\ Colección Jaimito n. ${ }^{\circ} 3$
}

Parentemente alejado del cómic desde hacía años,
Carlos Vermut, en 2012 ya reconocido por su opera
prima cinematográfica, Diamond Flash, retorna al medio donde nació como artista, para entregar lo que en principio parece una parodia de Dragon Ball. Como los demás tebeos de la colección Jaimito, la "grapa" se convierte en un vehículo de refinamiento en una edición mimosa y donde nada sobra. El texto de la solapa de portada, una parodia de la canción de apertura del anime de Goku, nos sitúa en un primer tramo de pura caricatura. Pero Vermut gusta de los géneros para manipularlos en experimentos en ocasiones crueles. La irrupción de un elemento externo a las fantasías de poder nipón que fue la primera mitad de Cosmic Dragon, supondrá un catalizador de reacciones imprevisibles. Redirige el relato, logra una lectura desasosegante, y convierte el género que supuestamente alojan los "jaimitos" en la navaja más afilada. Nada de ello sería posible sin un apartado gráfico muy depurado y que sabe moverse entre el manga más comercial y el alternativo norteamericano. $\mathrm{OB}$ 


\title{
La muerte en los ojos
}

\author{
David Sánchez, 2012 \\ Colección Jaimito n. ${ }^{\circ} 4$
}

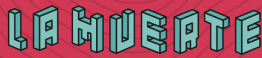

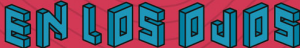

DATID SANMGHEZ

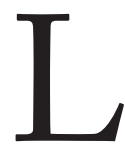

A primera ola de títulos editados en formato comic-book bajo la colección Jaimito se cierra con una obra ajena al humor. O no, porque los universos malsanos de David Sánchez admiten tantas interpretaciones que tampoco es absurdo analizarlas bajo el prisma de cierto sentido de lo cómico. Un sentido muy especial, arácnido, un misterio como un eco gaseoso dentro de un universo propio, que solo resuena en la cabeza de su autor. En todo caso, este objeto frágil, grapado, contiene la más acertada de las obras de David Sánchez. Lo es porque acentúa y enfoca sus logros pretéritos: vuelve a desgranar un ambiente, antes que relatar una historia, y la concisión obligada por el formato se convierte en la mayor ventaja para retratar un ambiente obsesivo, adictivo como adictos son los protagonistas. Desfile de coches Tiburón, radiocasetes, retratos ovales, pipas, penes, un loro y caballo del que se pincha. Hipnosis. ¿Es La muerte en tus ojos un relato de ficción o un mal viaje? ¿Queremos respuestas o preguntas? Ni unas ni otras ofrece el dibujo frío y pulido de Sánchez ni su espectacular sentido del color, emotivo en un sentido opuesto al sentimentalismo. La vida es sueño. Un ramillete de pesadillas. ов

HUMOR CRISTIANO

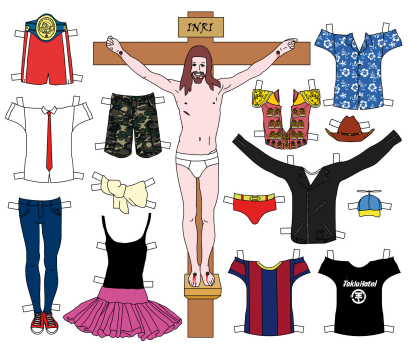

Alberto González Vázquez

\section{Humor cristiano}

\section{Alberto González Vázquez, 2012}

Ras un título y una cubierta deliberadamente provocadores, nos espera una recopilación del trabajo de Al-

- berto González Vázquez, colaborador de El intermedio y uno de los autores humorísticos más personales, extremos y libres que tenemos en el panorama nacional. Los límites del humor, ese debate recurrente, saltan por los aires en su obra, que parece no tener tabúes. Las drogas, el sida, la pederastia, la violencia machista... Todo puede ser objeto del humor si se hace de forma adecuada. Y González Vázquez, inteligentísimo, sabe cómo hacerlo. Sus historietas y textos están llenos de diálogos negros y brillantes, vueltas de tuercas inesperadas y rupturas de los márgenes de lo que puede decirse e incluso de lo que puede pensarse. A través de sus dibujos, calcos de fotografías, construye un universo frío y desolador, carente de buenos sentimientos y donde lo escatológico corre libremente, pero siempre tiene clara la dirección. Obama, Juan Echanove, Antonio Banderas, Amaral, Rafa Nadal... La descontextualización de figuras conocidas sirve como reclamo y al mismo tiempo como reflexión sobre el presente. Humor cristiano es uno de los mayores éxitos de ¡Caramba! - casi cuatro mil ejemplares vendidos-, y apareció acompañado de un vídeo promocional en la línea de la producción del autor en el campo de la animación, igualmente brillante y extrema. GV 


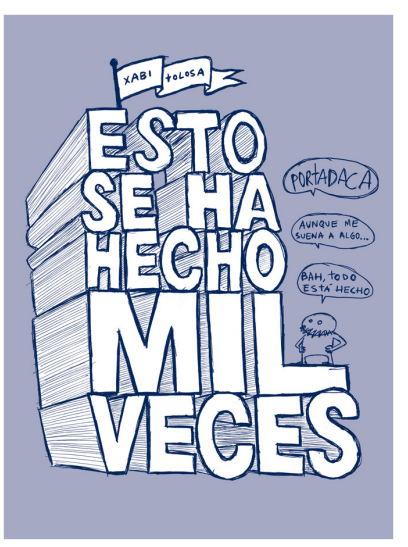

\title{
Esto se ha hecho mil veces
}

\author{
Xabi Tolosa, 2013
}

$\mathrm{D}$ E nuevo atendiendo a un pequeño fenómeno en la red, ¡Caramba! publicó esta recopilación de las pri meras temporadas del webcómic del joven actor Xabi Tolosa. Sin saber dibujar — sea lo que sea eso-, Tolosa se lanzó a contar pequeñas anécdotas de su vida cotidiana, en clave de humor y de forma espontánea, sin borrar o repetir. Sin pretensiones artísticas, el resultado es sorprendentemente fresco y divertido.

No solo por los gags y las situaciones graciosas que cuenta, sino por su dibujo simple, sus acotaciones, su sinceridad desarmante —-son impagables, por ejemplo, las notas explicando qué representa un dibujo que le ha quedado especialmente raro-. Desde sus inteligentemente asumidas limitaciones, Tolosa desarrolla una obra personal que emplea todo tipo de recursos gráficos: flechas, diagramas y tipografías... Su humanidad y tranquila forma de ver la vida impregnan todas las páginas y ganan a un lector que, cuando Tolosa se enfada y se erige en defensor de alguna causa, no puede hacer menos que jalear sus intentos un tanto pochos de hacer justicia. Mención aparte merece el secundario carismático: Camarón, el gato que convive con Xabi. Tras el éxito, Xabi Tolosa ha proseguido con el webcómic y ha producido una temporada de animación sobre el mismo. GV

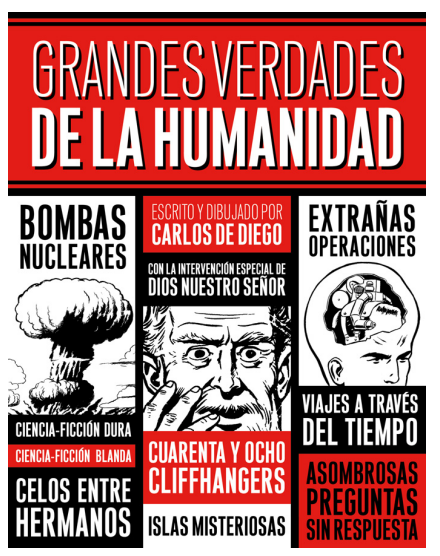

\section{Grandes verdades de la humanidad}

\section{Carlos de Diego, 2013}

1 utor esquivo donde los haya, Carlos de Diego llegó a Aublicar en El Víbora y El Manglar antes de centrarse 1 Len su trabajo audivisual con Los pioneros del siglo xxI. Gracias a ¡Caramba! vuelve al ruedo del cómic, con un trabajo brillante. Grandes verdades de la humanidad retuerce y se burla de las reglas clásicas del relato, y reformula los códigos del cómic tradicional de un modo muy alejado de la parodia o el pastiche típicos: Carlos de Diego recorta y modifica cabezas de personajes de comic-books cincuenteros y los pega sobre cuerpecillos inspirados en los tebeos de Bruguera. De esa mezcla marciana deriva una aventura por entregas, un folletín de serie B -islas desiertas, experimentos mentales, viajes dimensionales - que no da tregua y que, a base de bandazos en la trama, nos conduce a través de los avatares de una saga familiar en busca de una verdad que, por supuesto, nunca llega a ser revelada, y que funciona más bien como mcguffin de una obra que engancha por esa maravillosa sensación de que cualquier cosa puede suceder tanto como por el extraño y único sentido del humor de de Diego, más basado en las situaciones que en los gags. Seguramente fue el título más incomprendido del catálogo de ¡Caramba!, pero también uno de los mejores. GV 


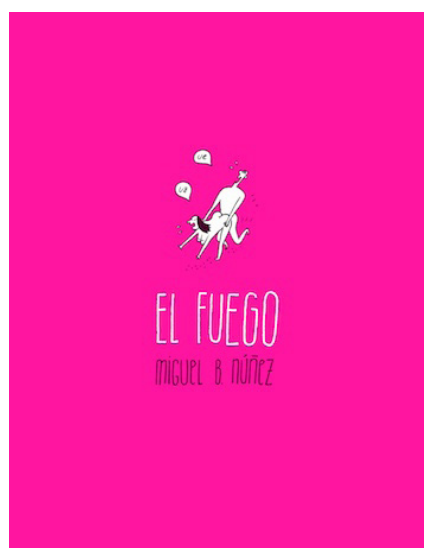

\section{El fuego}

Miguel B. Núñez, 2013

que crece y amenaza con consumirlo todo. Miguel B. Núñez entrega uno de sus mejores títulos, dibujado con un exquisito estilo minimalista y una intenció lúdica muy clara. Se trata de un cómic divertido y excitante, con fantásticas escenas de sexo y un slapstick resultón. GV

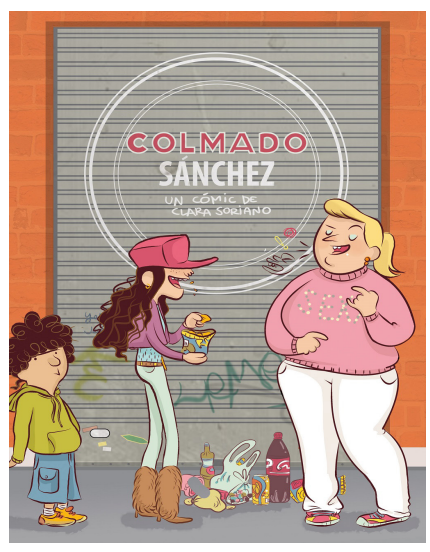

\section{Colmado Sánchez}

Clara Soriano, 2013

Colección Jaimito n. 5

"Joie de Vivre" contagiosa que son las mejores credenciales que podría blandir Soriano. Su dibujo es bonito en el mejor de los sentidos, sus escenas rezuman naturalismo y su narrativa clásica se apoya en unas páginas de elaboración igualmente clásica. La brevedad del formato quizá aquí juega en contra de una mayor profundidad, no para ser "trascendentes" si no para lograr un relato más sólido aún. Parece, en fin, un excelente capítulo piloto para una serie de cómic destinada a desbancar, por méritos, a tanta ñoñería catódica, usando sus mismos argumentos pero con mejores armas. ов 


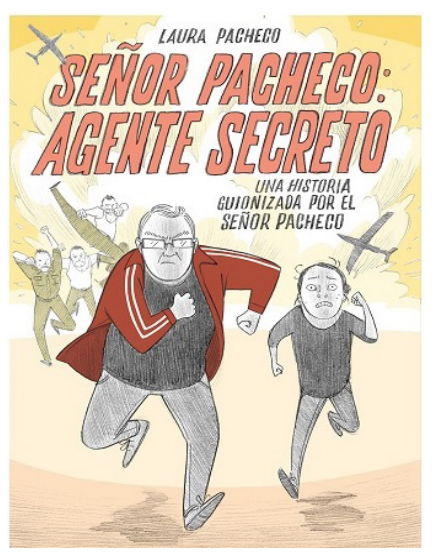

\title{
Señor Pacheco: agente secreto
}

Laura Pacheco y el señor Pacheco, 2013

Colección Jaimito n. ${ }^{\circ} 6$

Tras el éxito de Let's Pacheco y el webcómic que lo originó, Laura Pacheco retoma al personaje estrella de la Laga, el pater familias inefable, e incluso guioniza el cómic junto a él. El carisma del señor Pacheco es innegable, pero funciona mucho mejor en un contexto estrictamente humorístico y costumbrista. La aventura de género en Corea de Norte, con señor Pacheco e hija convertidos en agentes especiales, no resulta tan efectiva como las anécdotas con base real de las entregas breves, aunque el humor amable del cómic siga siendo divertido, y haya varios gags bien construidos. Lo mejor: el estilizado y sencillo dibujo de Laura Pacheco. GV

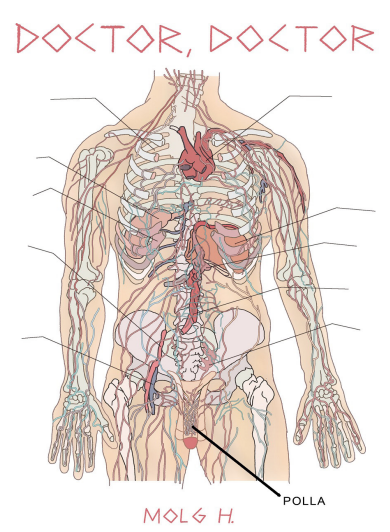

\section{Doctor, doctor}

\author{
Molg H., 2013 \\ Colección Jaimito n. ${ }^{\circ} 7$
}

$\mathrm{D}$

iciembre de 2013. A estas alturas de la trayectoria de

¡Caramba! está claro que una de sus facetas más interesantes es la de la búsqueda de las distintas caras de lo cómico. Doctor, doctor se asienta en el terreno del humor negro más desatado, convirtiendo cualquier chiste tópico de médicos en un paquete de minas estallando en el estómago del lector.

Molg H. (otro autor nacido en línea) exhibe un dibujo gélido como un quirófano y de trazos sencillos, con un leve aire a una procedencia fotográfica que no interfiere en la voluntad dubitativa de su trazo. Con una paleta cromática ideal para frigoríficos del futuro y mediante viñetas circulares sin contorno que pueden recordar a mirillas de puertas hospitalarias, Doctor, doctor es una colección de barbaridades que nos hacen intentar eludir la inevitable sonrisa. Otro vértice del humor, el opuesto a, por ejemplo, el de las hermanas Pacheco. Después de todo, "humor" también significa bilis, secreción, excreción, supuración, flujo y supurosidad. ов 


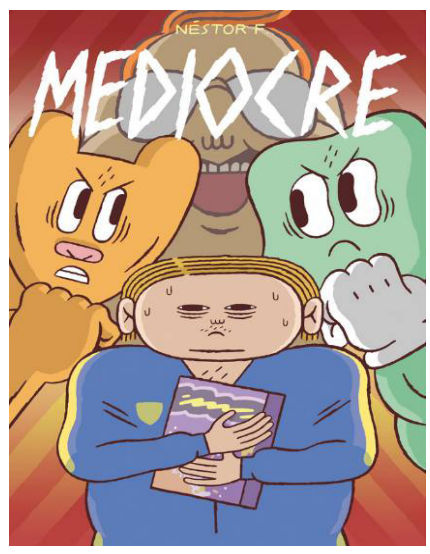

\section{Mediocre}

\section{Néstor F., 2013}

Colección Jaimito n. ${ }^{\circ} 8$

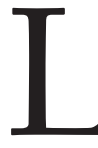

A segunda entrega de las andanzas de Bruno Kolin no supuso ninguna adición significativa a la creación de Néstor F.; es otra aventura más de un personaje que pedía otra dirección. Sin embargo en el choque entre el viejo crítico -Kolin - y el joven videoblogger que lo suplanta se lee la brecha cultural de nuestra época, y eso es un valor a tener en cuenta. Por lo demás, algún momento inspirado, un dibujo aún mejor que en la primera entrega de un dibujante excelente, y las andanzas lisérgicas de un Bruno Kolin que decide suicidarse a base de una sobredosis de pastillas y acaba asumiendo una misión especial de salvamento que termina en una humillación final. Sigue dejando la sensación de que el personaje da para más, pero Néstor F. parece embarcado en nuevos - e interesantes- proyectos. GV

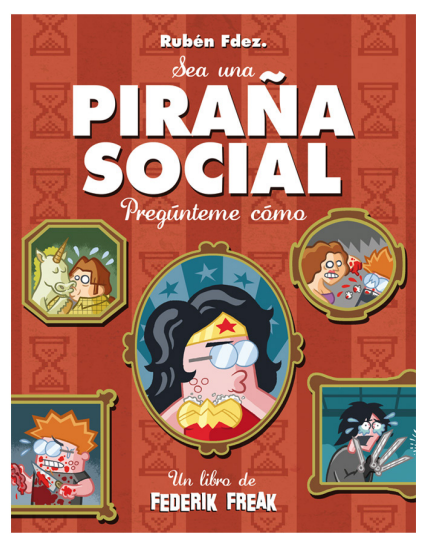

\section{Piraña social}

Rubén Fdez., 2013

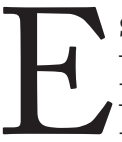

STE libro recopila las páginas del personaje Federik Freak aparecidas en El Jueves, obra del popular $\mathrm{Ru}$ - bén Fdez. Es, como puede imaginarse, uno de los títulos más convencionales aparecidos bajo el sello de ¡Caramba!, pero eso no significa que no sea muy divertido. "Federik Freak" es una parodia de la cultura friki, de esas masas cuyas vidas parecen girar en torno al último capítulo de su serie favorita o al próximo reboot de una saga cinematográfica de culto. Las situaciones están tan pasadas de vueltas que ofenderse es absurdo, pero la serie tira certeros dardos dirigidos a la insoportable seriedad de algunos fans y a la nostalgia acrítica, principalmente. La visión distorsionada de la realidad que tienen sus protagonistas refleja la de cualquier subcultura que cree que toda la sociedad se mide por su escala de valores, y por eso, aunque la crítica sea horizontal en tanto que Rubén Fdez. es también fan, dicha visión acaba siendo grotesca y patética. Un mérito más: puede que la serie no sea muy profunda ni admita múltiples lecturas, pero no cae en la repetición de otras. GV 


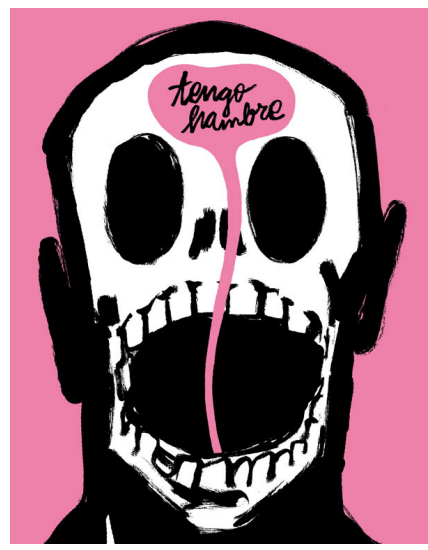

\section{Tengo hambre}

Santaiago García y Manel Fontdevila, 2014

7 ENGO hambre, tebeo que adopta el formato comic-book pero separadamente de la colección Jaimito, es uno de 1 los desafíos más sólidos a la preponderancia temática de ¡Caramba!, pues aunque el humor tiene su peso no se trata, desde luego, de un ejercicio de género puro. Escrito en 2005 por Santiago García, se materializa casi diez años más tarde, con el concurso de un fabuloso Manel Fontdevila para, juntos, perpetrar una fábula cáustica, entre el horror y el humor esperpéntico, sobre las desigualdades sociales y el rodillo cruel de España (y Europa) con respecto a la población inmigrante. Como suele ocurrir en la obra de García, la literalidad de su trama y el nudo central de su argumento son lanzaderas para explorar temas diversos, como el darwinismo humano. Y Fontdevila muestra un dominio arrollador de los recursos del medio, construyendo una pesadilla entre lo cotidiano y lo surreal donde las sombras, las luces y los grises solo saben amenazar. Apurando la capacidad de los géneros para desfigurarse y entremezclarse, García y Fontdevila encuentran un cruce estremecedor entre el berlangianismo y el gore. OB

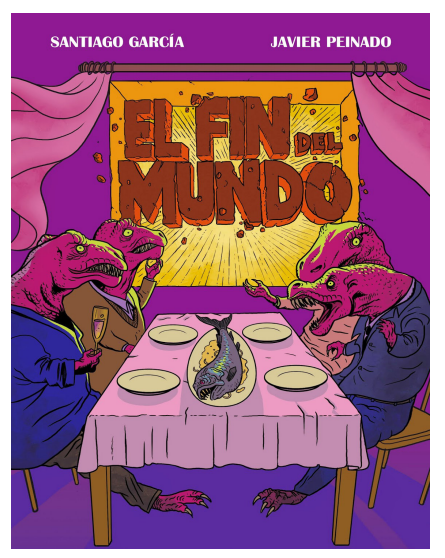

\section{El fin del mundo}

Santiago García y Javier Peinado, 2014 Colección Jaimito n. ${ }^{\circ} 9$

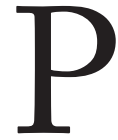

EINADo y García ya habían colaborado con anterioridad —en La Tempestad y Héroes del espacio, de 2008 y 2009 respectivamente - con lo que podemos decir que estamos ante el primer caso de un equipo creativo con solera que entra a formar parte del catálogo de ¡Caramba!. El Fin del Mundo, publicado al alimón con Tengo Hambre, medio año después de Beowulf (García y David Rubín, Astiberri) y pocos meses antes del sensacional Fútbol, la novela gráfica (García y Pablo Ríos, Astiberri) y la obra maestra Las Meninas (García y Javier Olivares, Astiberri), es un trabajo que revela claramente la categoría de su guionista. Perfectamente acompañado por un Peinado imprescindible, que aporta con su dibujo de raíz francobelga y naturalista el toque de realismo sucio imprescindible para esta historia. Aunque su resumen - y su portada - pudiera parecer una astracanada, este "a day in the life" analiza los mecanismos de la derrota, el paisaje social de la crisis, el poder de los mitos, el papel del cómic como vehículo de símbolos, el papel social del arte (y del cómic, claro) y el poder sanador de la ficción, incluso. Y de postre indaga en los recursos del cómic con brillantez. ов 


\title{
23 fotogramas por segundo
}

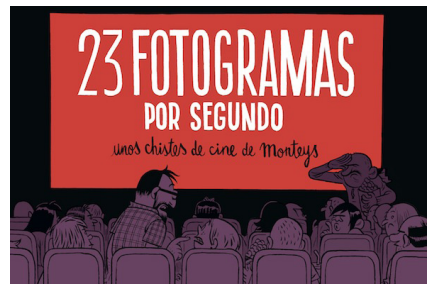

\author{
Albert Monteys, 2014 \\ Colección Jaimito n. ${ }^{\circ} 10$
}

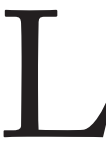

As historietas publicadas en este cómic fueron originalmente publicadas en El 50, diario del Festival In-

ternacional de Cine de Gijón, y no se me ocurre mejor modo de saborearlas que entre culines de sidra bien escanciada al lado de la playa. Sin alcanzar las cotas de su oda al macho-man Ser un hombre, la naturaleza de encargo no hace mella, no obstante, en la riqueza de soluciones de Monteys, y desde luego vuelve a demostrar la capacidad de resultar simpático de un modo incontestable incluso si le encargasen ilustrar la letra "V" de las páginas amarillas de su pueblo. Y por muy interesante que sea la "V" evidentemente el mundo del cine lo es más. Un campo abonado para el humorista observador. Así que Monteys, una lupa andante, entrega un montonazo de observaciones lúcidas sobre el cinematógrafo y todo lo que lo rodea: escenas tópicas, frases tópicas de la crítica, los tráileres, tipos de espectadores... El formato horizontal nos recuerda la pantalla panorámica, y acentúa el ejercicio de sólida retícula en la página, que Monteys no se salta jamás. El dibujo se muestra versátil, acaso por su origen de entregas, y destaca en momentos donde opta por el cuasi-boceto. ов

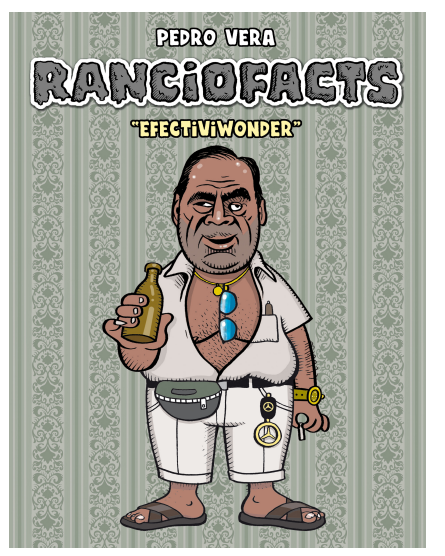

\section{Ranciofacts}

\author{
Pedro Vera, 2014
}

$\mathrm{E}$

sTe libro fue el último que ¡Caramba! publicó como editorial independiente, y se convirtió en uno de sus grandes éxitos, al agotar la primera tirada de dos mil ejemplares en tan solo un mes. Organizada en páginas temáticas, esta "Biblia ilustrada de la cultura cuñao" es un reflejo menos esperpéntico de lo que nos gustaría de nuestra identidad nacional. A través de frases hechas, tópicos, creencias y costumbres, retrata grotescamente muchos de los problemas que España arrastra con su idiosincrasia histórica. Por eso uno no sabe si reír o llorar con este museo de los horrores ibérico, que rescata de la memoria del país suficientes argumentos como para olvidarnos de pensarnos modernos y describe con minucioso afán sociológico al español medio, ese cuñao soberbio, narcisista y paleto que como bien dice Raúl Minchinela en su excelente prólogo, es en parte culpable del atraso del país. GV 


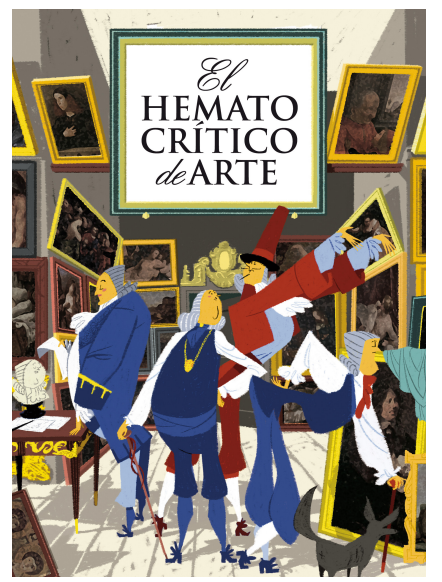

\title{
Otros productos
}

\author{
Varios autores, 2011 1-2014
}

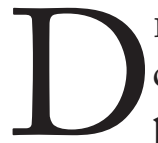

ESDE el principio de su andadura, ¡Caramba! ofreció en su catálogo otro tipo de producto además del principal: los cómics. Sin duda los más importantes fueron los libros del Hematocrítico, un personaje célebre en redes sociales con una preclaridad indiscutible a la hora de crear tendencias. Su Tumblr sobre arte, en el que descontextualizaba cuadros clásicos al añadirle nuevos títulos, se tradujo en dos exitoso libros, El Hematocrítico del arte 1 y 2. Cuando da en el clavo con esa fórmula, es hilarante, y ha generado clásicos inmediatos del humor. Drama en el portal, que contó con diseños adicionales de Mauro Entrialgo, es una recopilación de fotografías de carteles colocados en portales por vecinos cabreados, que los seguidores del correspondiente Tumblr enviaban al Hematocrítico.

Otro producto aparecido en fechas tempranas fue Los fabulosos Teykerman de Pedro Villarejo, una colección de láminas que homenajean a una inexistente línea de muñecos de los años ochenta y que reproducen a cuarenta y ocho personajes cinematográficos. Otros cinco juegos de láminas - con un menor número de ellas - se pusieron a la venta: Holocausto Australopithecus de David Sánchez, que se regalaba en forma de álbum de cromos con la compra on line del primer fanzine, Miembros fugaces de Paco Alcázar, Final de liga de Albert Monteys, Humor amarillo de Néstor F. y Guerreros chulos con armas guapas de Nacho García.

Por último, el seguidor de ¡Caramba! también podía adquirir una camiseta con la inmortal pregunta “¿Ha visto usted a Mistetas?” y un póster con la ilustración de Albert Monteys para la portada del fanzine inaugural. GV 